\title{
MODELING VEHICLE USAGE, MODE CHOICE AND TRIP CHAINING FOR MULTIPLE HOUSEHOLD MEMBERS IN DEVELOPING COUNTRIES
}

\author{
Dilum DISSANAYAKE ${ }^{1}$ and Takayuki MORIKAWA ${ }^{2}$ \\ 'Student member of JSCE, M. Eng., Postgraduate Student, Dept. of Civil Eng., Nagoya University \\ (Chikusa-ku, Furo-cho, Nagoya 464-8603, Japan) \\ ${ }^{2}$ Member of JSCE, Ph.D., Professor, Graduate School of Environmental Studies, Nagoya University \\ (Chikusa-ku, Furo-cho, Nagoya 464-8603, Japan)
}

\begin{abstract}
This study attempts to investigate household decisions on vehicle usage, mode choice and trip chaining in developing countries using a multi-level nested logit (NL) model. The nesting structure represents the choices of vehicle usage, vehicle selection and mode selection for two-traveler households. Household serving chain is entered as one of the mode-choice options in the developed NL model and attributes relating to the household travel are explicitly incorporated in the analysis. A congestion reduction policy considering a "push and pull" concept is also conducted using the estimated NL model. The model and the policies are verified using the data from Bangkok Metropolitan Region.
\end{abstract}

Key Words: developing countries, vehicle-ownership, trip chaining, multiple travelers, congestion reduction

\section{INTRODUCTION}

Traffic congestion is considered as a critical issue in developing countries due to rapid increase in vehicle-ownership and usage. Transport users in such countries are truly unsatisfied about the inferior services offering from public transportation that encourage them to own and use vehicles for daily necessities. Although they have great intention to own a vehicle, owning multiple vehicles are not very popular among the developing country households' due to the prevailing economic instability. Therefore, limited number of vehicles in each household should be efficiently utilized for the travel related daily activities belonging to the household. Consequently, the individual who commutes by a vehicle has to get the burden of driving for other household members, and as a result, the direct commuter travel has been turned into a frequent multipurpose trip by enhancing the travel related household responsibilities.

A multipurpose tour, in other words, a trip chain is defined as a linkage of different types of purposes by imposing several intermediate stops ${ }^{1), 21}$. By observing person-trip survey data in developing countries, it has been observed that there exists a considerable motivation for the formation of car and motorcycle trip chains to deal with numerous travel necessities, for instance, giving a ride, shopping, personal business, social and recreation. It implies that the trip chain is a timely requirement in daily commuting, especially for the vehicle owning households in developing countries.

Trip chaining is an effective travel option if the destinations of the travelers are close to each other, and they can avoid two or more separate homebased car tours. However, the situation prevailing in Bangkok is found to be different. Very few households own two or more cars and travelers make trip chains even though the destinations are distantly located, and most of the cases, they need to touch the far ends of the main city to make trip chains. The basic reason for this is mainly due to the inefficient services of public transportation as mentioned before, and travelers are attempting to form trip chains rather than using public transportation or owning multiple cars. Apparently, commuters frequently cross $\mathrm{CBD}$ to serve other household members, contributing to heavy traffic congestion.

Therefore, it is very important to make emphasis on behavioral aspects of vehicle usage and trip chaining for the investigations of congestion reduction policies. Most of the previous researches 


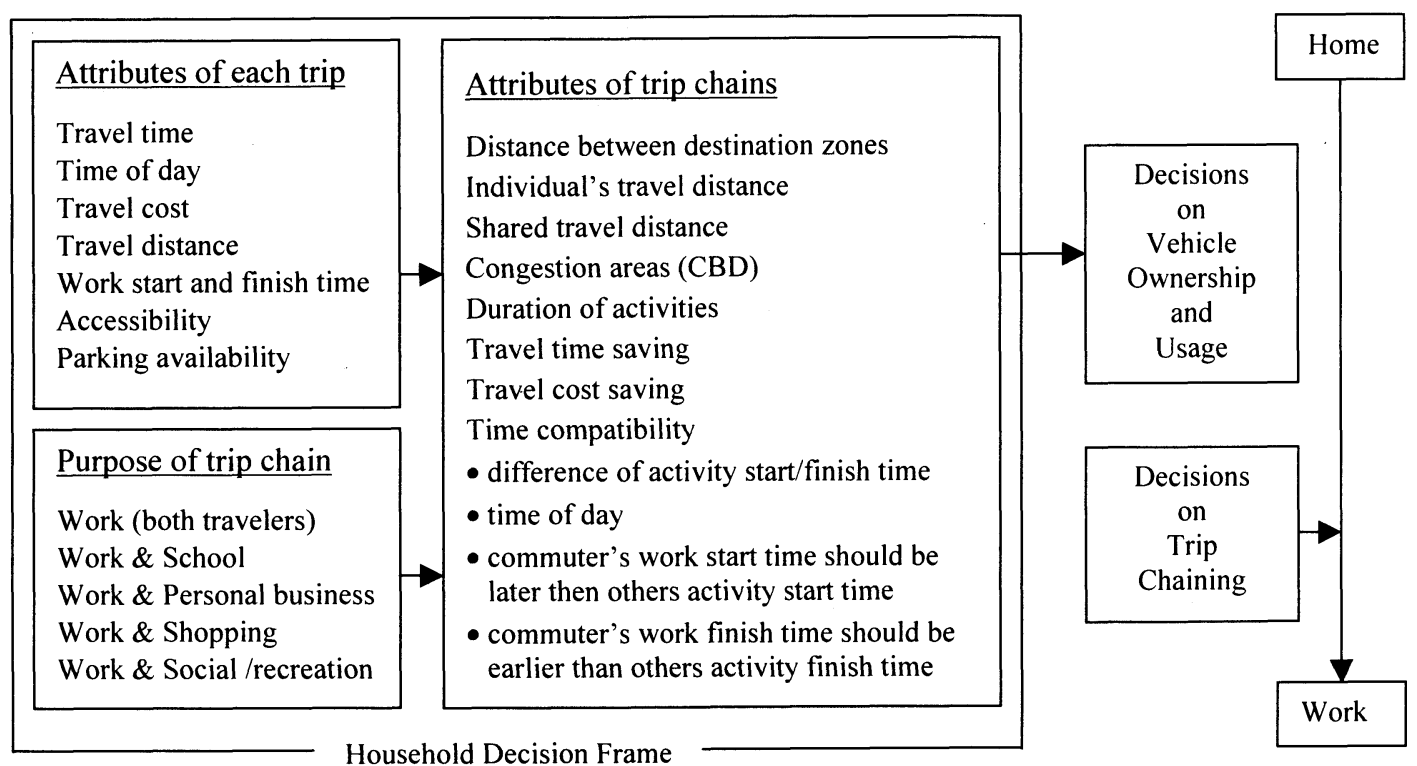

Fig.1 Integration of household travel decisions into a commuting based trip

in trip chaining aspects and activity based analysis focused on individual travel behavior ${ }^{1,2,3)}$ and comparatively less effort has been made on household behavior due to the complexity of the household travel pattern.

This study aims to investigate household decisions on vehicle usage, mode choice and trip chaining in developing countries using a multi-level nested logit (NL) model. Analysis is based on commuter travel and two-traveler households are specifically taken into consideration. The estimated NL model is also applied for congestion reduction policy analysis emphasizing "push and pull" concept by implementing a vehicle tax in addition to the subsidization of public transportation in urban areas. The model and the policies are verified using the data from Bangkok Metropolitan Region.

\section{HOUSEHOLD ATTRACTION ON TRIP CHAINING}

The commuting based trip chains accompanied with vast variety of household desires have to comply with the requirements persistent on each individual, who benefits from the trip chain with minimum deviation of the commuter's travel schedule. Therefore, considerable degree of flexibility in the service level is involved in the decisions on trip chaining (Figure 1).

\section{REVIEW OF THE LITERATURE}

In recent years, investigations on individual's daily commuting travel pattern have been diverted into a complex trip-chaining pattern since the simple trip based analysis does not adequately explain the interdependencies of the chain links ${ }^{1,2), 4), 5}$. The overall utility of the chain increases with increasing trip links ${ }^{4)}$. Wegmann and Jang ${ }^{1)}$ developed a statistical model for complex trip chaining behavior of individuals and identified that individuals who work in urban areas have fairly high attraction for the complex chaining behavior. It also reveals that the individuals, who use public transportation, prefer very simple commuting pattern rather than making complex trip chains. Jou and Mahmassani ${ }^{2)}$ made emphasis on the commuter's attributes, work place conditions and travel attributes in their study and found that the commuters are more likely to make stops during evening work-to-home trips. The concept of individuals' trip-chaining behavior was further investigated by integrating trip-chaining behavior with destination choice analysis. Kitamura $^{5)}$, for instance, explicitly considered the attributes relating to the destination choice attractions. Trip generation and trip chaining behavior were statistically analyzed by Goulias and Kitamura $^{6}$. In their study, trip chaining was simply explained using a regression model and then, it was extended to identify the behavioral variations for income, city size and car-owning sub groups. 
Gender variation of household serving trips was also investigated in previous studies. Mauch and Tailor $^{7)}$ found that female participation for the household serving trips in Asian countries was considerably low compared to other countries. It was also mentioned that males in Asian countries highly contribute for child-serving trips.

Multinomial logit model (MNL) was widely applied for the travel demand analysis during last two decades. It has however rather very strict assumption of independence of irrelevant alternatives (IIA). Therefore, its applicability in analyzing complex travel patterns is not very reliable. Adler and Ben-Akiva ${ }^{4)}$ investigated household behavior on trip chaining using MNL where the household attributes such as scheduling convenience, travel time, travel cost, destination characteristics and socio-economic measures were taken into consideration. Using the estimated model several policies have been analyzed by changing gasoline prices and transit fares. Strathman et al. ${ }^{8)}$ expressed work commute chains as discrete alternatives and modeled the chain behavior using a binary logit model to find the attraction of integrating non-work trips into a commuting based trip chains. They also developed a statistical analysis for the attraction of allocating non-work travel into multi-stop non-work and unlinked nonwork chains.

Nested logit (NL) model is an advancement of the MNL where the property of IIA is relaxed into some extent. Sobel ${ }^{9)}$ made emphasis on travel demand forecasting for individuals, and various types of $\mathrm{NL}$ structures were incorporated for the mode choice analysis. When the journey consists of multiple modes such as $K \& R$ or $P \& R, N L$ is a suitable tool to analyze the choice behavior considering the similarities of unobserved attributes in particular sub-groups ${ }^{10)}$. Commuting-based mode choices were estimated by using a two-level NL model considering upper level for line haul choices and lower level for access/egress modes, and extended the study for market segmentation considering income and work trip sub-groups ${ }^{11}$. There is also an increasing interest in activity-based approaches in recent years ${ }^{11), 12)}$. Mannering et al. ${ }^{12)}$ investigated individuals' activity type choice as well as activity chaining aspects using a NL model, where lowernest represents number of stops in the activity chain and upper-nest shows activity type choice. BenAkiva and Bowman ${ }^{3)}$ developed a model for individuals' daily activity schedules and the methodology was basically split into three interrelated considerations such as daily activity pattern, primary tour and secondary tours.

Mathematical programming was also used to investigate household activity pattern where the objective function was formulated as maximization of utility and the constraints were related to activity pattern $^{(3)}$. It also discusses the main difference of mathematical programming over other techniques used for travel behavior investigations such as logit, probit and regression where the choices are assumed to be unconstrained.

Most of the existing studies made attention on various policy implementations to reduce environmental externalities, for instance air pollution ${ }^{14), 15)}$ and congestion ${ }^{16)}$. According to Himanen $^{16)}$ congestion is a common problem in developed countries as well. Scott et al. ${ }^{17)}$ investigated the way of improving commuting efficiency by considering the locational choices of workers. As mentioned by Salomon ${ }^{18)}$, there exists some gap between policy assumptions and actual travel behavior and analysis was made to visualize the reasons of such differences.

\section{PROPOSED MODEL STRUCTURE}

\section{(1) Data description}

The data for this research were obtained from the household travel survey conducted in the Bangkok metropolitan region, which consists of 505 internal traffic zones. The Urban Transport Database and Model Development Project (UTDM) was responsible for the survey that was conducted during 1995/96. The survey provides wide variety of data relating to the travel behavior considering all the attributes of the trips made on the date of survey as well as the personal information of the entire household ${ }^{19}$. Although there were large amount of households in the database, 1205 households were selected for the empirical analysis according to the model requirement of two-traveler households where one of the travelers should strictly be a commuter. Commuter (main traveler) trip can either be home-to-work or work-to-home, and there are no any restrictions regarding to the trip purpose of the second traveler.

In the database, daily trips were indicated using the origin and the destination zones for each traveler with independent mode (unlinked) trips. Therefore, it is easy to distinguish the interrelations among the trips for both travelers such as work related trip chains, transfer modes, zones and time of the transfers. Geographical information of the study region was computerized by Mapinfo Geographical Information System based Arc-view software, which is helpful for easy reference and meaningful comparison whenever necessary. Furthermore, location-based information such as trip length is 
Mode choice representation:

1. Commuter mode

2. Second traveler mode

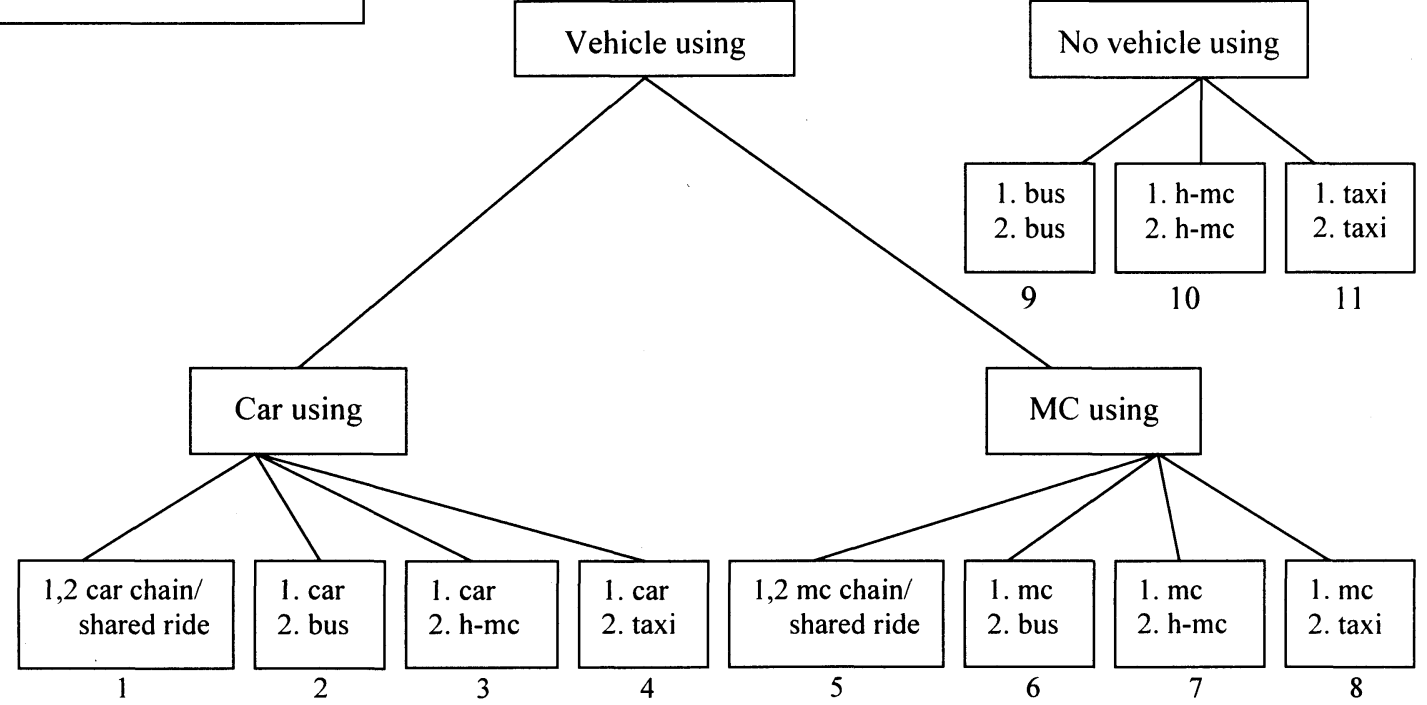

Fig.2 Nested logit model for two-traveler households

measured using the criteria of the shortest distance between origin and destination zones.

An additional database for home interview survey was provided by Bangkok Environmental Improvement Project (BEIP), which supports to strengthen the overall database ${ }^{20)}$.

\section{(2) Modeling approach}

In the selected study region, overall set of transportation modes consists of bus, rail, car, motor cycle $(\mathrm{mc})$, hired motorcycle (h-mc), taxi and ferry. Since rail and ferry transport services provide inefficient service and limited accessibility, travelers' attraction is comparatively low in using such modes. Therefore, universal choice set of transport modes for the study excludes the rail and the ferry options. Therefore, vehicle-using households have choice options of car and $\mathrm{mc}$, and no vehicle-using households have choices of bus, hired motorcycle and taxi. This study explicitly considers two-traveler households and therefore, one or combination of the aforementioned modes dominates the household travel behavior.

In discrete choice analysis, utilities for choice alternatives are considered as random variables ${ }^{21)}$. Therefore, the total utility was expressed as the summation of the systematic (deterministic) and random components. The systematic component can be easily obtained by the measurable attributes relating to each choice option, while the random component includes all the other effects on the choice context. Development of a modeling structure is basically relied on the nature of this random component of utility.

Among the vast variety of techniques existing for the analysis of travel behavior, a NL model is selected for this study mainly due to the requirement of taking group-wise relations of alternatives into consideration.

NL model is generally developed as a hierarchical structure to represent the correlation of unobserved effects by forming mutually exclusive and collectively exhaustive choice sets to relax the strict assumptions of IIA in the MNL. Each individual nest in the NL structure shares common component of random utility in addition to the alternative specific random component. When the sharing component of random utility of the nest is zero, the model is simply converted into a MNL ${ }^{22}$.

The NL structure developed for the two-traveler households is shown in Figure 2. The lowest level of the nesting structure represents the alternatives for car using and mc using households. Alternatives $1 \sim 4$ are applicable for car using households where the commuter (main traveler) travels by car and the second traveler has options of selecting car chain/ shared ride, bus, hired motorcycle $(\mathrm{h}-\mathrm{mc})$ or taxi respectively. As described earlier, alt. 1 4 share 
common component of random utility considering the level of comfort, safety, convenience, privacy as well as all other unobserved attributes relating to the car use. Similarly, alternatives $5 \sim 8$ are applicable for mc using nest. For the households who do not use any private vehicles, alternatives $9 \sim 11$ are applicable where both travelers use bus, hired motor cycle or taxi depending on their convenience.

According to the data from household travel survey, distribution of households over alternatives $1 \sim 11$ are graphically represented in Figure 3. It indicates that bus alternative has the highest usage (37\%) followed by the me chain $(16 \%)$ and car chain $(13 \%)$.

The variance of the random utilities increases with moving from the lowest level to the upper level of the NL model ${ }^{21)}$. It also means that, largest scale parameter exists at the bottom level and it decreases with increasing level. Another important insight of the NL model is a measure of the composite utility, also called the expected value of the maximum utility of the nest that can be obtained by taking the $\log$ sum of the exponents of the nested utilities for all the alternatives included in the nest. The composite utility relating to the lower nest (log sum) has to be appeared in the utility function of the upper level after adjusting for the scale parameter.

\section{(3) Estimation procedure}

Simultaneous estimation (full information maximum likelihood) method is used for the estimation of the developed NL structure. Basically, it is assumed that scale parameter for the mc nest is unity and then, the scale parameters for the other levels are estimated.

Attributes, which are obtained from the data, are explicitly incorporated for the analysis to contrast the behavioral realism on vehicle usage and its associated effects on trip chaining for two-traveler households.

This study is based on two-traveler household and therefore, socio-economic variables for both travelers are appropriately calculated and applied for the model estimation. For example, travel time for alternative 2 (car \& bus) is obtained by adding commuters' travel time (car travel) and the second travelers travel time (bus travel).

\section{ESTIMATION RESULTS AND DISCUSSION}

Table 1 shows the parameter estimates for the developed NL structure. Most of the parameters are significantly estimated with expected signs in the sense of explaining household travel behavior in developing countries.

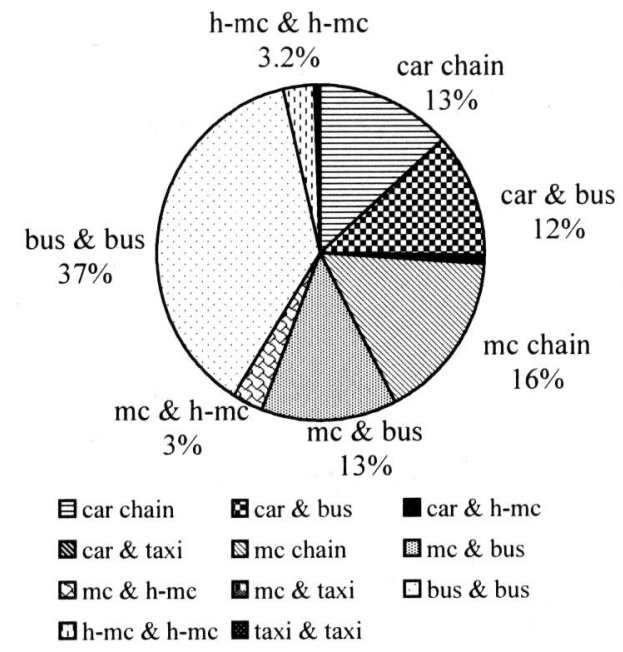

Fig.3 Distribution of households with modal selection

Alternative specific constants of alternatives 2 and 6 that are estimated with positive significance indicating that many households are attracted to the car and bus as well as $\mathrm{mc}$ and bus alternatives. Alternative specific constants for alternative 1 is estimated with negative significance implying that the households are likely to avoid car chain/ shared ride if all the other attributes are in the same level.

Coefficients for the travel time and the travel cost/income are meaningfully estimated with negative sign with adequate significance.

All the scale parameters are correctly estimated between 0 and 1 and the magnitude of those parameters are decreasing with increasing level of the nesting structure as expected.

Initially, it was assumed that:

$$
\mu^{m c c h / m c b / m c h m c / m c t}=1
$$

Using the above assumption, equations (2), (3) and (4) can be written as follows:

$$
\begin{gathered}
\mu^{\text {mcch/mcb/mchm/mct }} \geq \mu^{\text {car/mc }} \geq \mu^{\text {veh/no veh }} \\
1 \geq \mu^{c c h / c b / c h m / c t} \geq \mu^{c a r / m c} \geq \mu^{\text {veh } / \text { no veh }} \\
\mu^{\text {bus / hmc/taxi }} \geq \mu^{\text {veh/noveh }}
\end{gathered}
$$

Values obtained for the scale parameters are estimated between the limits specified by the equations (2) (4). All the scale parameters are significantly estimated despite of the insignificance related to the upper level parameter. 


\begin{tabular}{|c|c|c|}
\hline Variable description & $\begin{array}{c}\text { Estimated } \\
\text { parameters }\end{array}$ & t-statistics \\
\hline \multicolumn{3}{|l|}{ Alternative specific constants } \\
\hline 1 - car chain/shared ride(cch) & -4.46 & -2.8 \\
\hline 2 - car \& bus(cb) & 2.50 & 3.1 \\
\hline 4 - car \& taxi(ct) & -0.08 & -0.1 \\
\hline 5 - motor cycle chain/shared ride(mcch) & -0.98 & -1.3 \\
\hline 6 - motor cycle $\&$ bus (mcb) & 1.04 & 4.4 \\
\hline 8 - motor cycle \& taxi (mct) & -1.43 & -2.3 \\
\hline motor cycle using (mc) & 0.98 & 0.3 \\
\hline $9-\operatorname{bus}(b)$ & 11.24 & 1.3 \\
\hline 10- hired motor cycle (h-mc) & 3.32 & 1.0 \\
\hline No vehicle using (nvu) & 3.01 & 0.3 \\
\hline \multicolumn{3}{|l|}{ Level-of-service variables } \\
\hline travel time (hrs) & -0.76 & -2.7 \\
\hline travel cost/income $/ 10^{2}$ & -4.56 & -3.8 \\
\hline \multicolumn{3}{|l|}{ Scale parameters } \\
\hline$\mu^{c c h / c b / c h m / c t}$ & 0.810 & 4.2 \\
\hline$\mu^{c a r / m c}$ & 0.294 & 2.0 \\
\hline$\mu^{\text {bus /hmc/taxi }}$ & 0.288 & 1.6 \\
\hline$\mu^{\text {veh/no veh }}$ & 0.285 & 2.1 \\
\hline
\end{tabular}

\section{Alternative specific dummies}

distance between destination zones $\leq 15 \mathrm{~km}$, cch \& mcch $\quad 1.48$

male commuter, cch \& mcch $\quad 1.27 \quad 3.4$

time compatibility, cch $\quad 6.66 \quad 3.3$

(commuter's work start time should be later than others activity start time, or

commuter's work finish time should be earlier than others activity finish time )

trips touching CBD, cb

$1.61-3.1$

commuter's job(executive), mcch

$-1.41-5.3$

travel distance for both travelers $>20 \mathrm{~km}$, mcch

$-0.78-1.5$

travel distance for both travelers $>30 \mathrm{~km}, \mathrm{cb}$

$2.19-1.8$

distance between destination zones $\geq 15 \mathrm{~km}$, mcb

$0.50 \quad 1.2$

car driving license, car using

$15.20 \quad 2.0$

mc driving license, mc using

24.8

2.1

trips within $\mathrm{CBD}$, vehicle using

$-2.93$

$-1.8$

commuter's job(executive or business), vehicle using

3.94

1.9

no vehicle and no driving license, nvu

13.74

1.8

Number of observations

$L(\hat{\beta})$

$L(c)$

VOT (Baht/hr) 
Using the estimated values for the scale parameters, parameter for log sum variables can be easily calculated. Therefore, considering car using, mc using, vehicle using and no vehicle using nests, parameter for log sum variables are calculated as $0.36,0.30,0.97$ and 0.98 respectively. Those values are estimated in the theoretically acceptable range between 0 and 1 and values for vehicle using and no vehicle using nests are very close to 1 implying that upper level of the NL model has closely been characterized with simple MNL.

Most of the dummy variables explicitly highlight the behavioral trend on trip chaining characteristics as well as vehicle using aspects. The dummy variable for time compatibility mainly compares both travelers' activity start/finish times that are estimated with positive significance to represent the true behavior of car chaining. In other words, if the commuter's work start time (finish time) is later (earlier) than the second travelers' activity start time (finish time), it encourages them to make a car chain. When the distance between destination zones is less than or equal to $15 \mathrm{~km}$, parameter is estimated with positive significance highlighting the household tendency to make car and motorcycle chains. If the distance between destination zones is greater than or equal to $15 \mathrm{~km}$, household tendency is diverted to choose the alternative of motorcycle and bus, where commuter uses motorcycle by allowing second traveler to use bus.

Dummy variables for male commuters that are included in car chain and mc chain alternatives are significantly yielded with positive sign expressing their contribution for households' travel responsibilities.

For the trips that touch the CBD zone, car and bus alternative is dominating. In other words, traveling through CBD zone, especially in Bangkok Metropolitan Region, is extremely time consuming during commuting hours and therefore, the commuter drives alone allowing the second traveler to select bus rather than trying to form a trip chain in the said zone.

If the travel distance of each traveler is more than $20 \mathrm{~km}$, motorcycle chains is less likely to be performed. Similarly, if the travel distance of each traveler is more than $30 \mathrm{~km}$, car and bus alternative is dominating rather than making trip chains for long travel distances.

Commuter's job condition is also analyzed by introducing the dummy variable in the alternatives of vehicle using as well as motor cycle chain. When the commuter's job is either executive or business oriented, the parameter is estimated with positive sign indicating their preference for using a vehicle to demonstrate the power and reputation linking with the job condition. Also, executive job oriented commuter shows negative tendency to create motor cycle chains since the related dummy is estimated with negative sign with high significance.

There exists very high positive significance for the dummy of commuter's driving license over car using and mc using alternatives proving the basic requirement of vehicle use. No vehicle and no driving license dummy is introduced for no vehicle using households and it yielded with expected sign.

$L(c)$ is obtained by considering only the scale parameters while keeping all other parameters to be zero.

In general, VOT is a measure that represents the external validity of the estimated model, and it is calculated by using the coefficients of travel time and travel cost. According to the specification of our model, VOT also depends on household income in addition to the coefficients of travel time and travel cost. Since the data set has variety of household incomes, there exist different VOT figures for each household. Therefore, average VOT is calculated according to the equation (5).

$$
\operatorname{VOT}=\left(\frac{\text { coefficient of travel time }}{\text { coefficient of travel cost } \text { income } / 10^{2}}\right) *\left(\begin{array}{l}
\text { Average } \\
\text { Income }
\end{array}\right)
$$

From the estimated NL model, average VOT is obtained as $28 \mathrm{Baht} / \mathrm{hr}$. The obtained value of VOT is very similar to the value that was obtained from the previous investigation in the same region by UTDM project ${ }^{19)}$. It implies that the estimated model is intuitively sensitive to behave with the actual circumstances in the area concerned.

\section{POLICY ANALYSIS}

\section{(1) Overview of congestion problem}

Recent behavioral changes relating to household mobility, especially vehicle using and trip chaining aspects highly contribute to traffic congestion in developing countries. Therefore, developed NL model is effectively applied to overcome the barriers to curb congestion by investigating some attractive policy measures.

To find a tractable solution for the ever-expanding traffic congestion, it is very important to restrain vehicle usage in $C B D$ areas. Although there is an increasing emphasis that has been placed upon promoting public transportation for instance, service improvements, fare reduction and capacity expansion, it will not be sufficient to decline the 
Table 2 Modal share variations with policy issues

\begin{tabular}{|c|c|c|c|c|c|c|c|}
\hline \multirow[t]{3}{*}{ Choice alternative } & \multirow[t]{3}{*}{ Actual case } & \multicolumn{6}{|c|}{ Predicted cases } \\
\hline & & \multicolumn{6}{|c|}{ (40 Baht vehicle tax for CBD travel with \% reduction of transit fares) } \\
\hline & & $-50 \%$ & $-40 \%$ & $-30 \%$ & $-20 \%$ & $-10 \%$ & $0 \%$ \\
\hline 1 - car chain & 13.29 & 12.81 & 12.86 & 12.91 & 12.96 & 13.01 & 13.07 \\
\hline 2 - car and bus & 11.86 & 11.49 & 11.46 & 11.42 & 11.39 & 11.36 & 11.33 \\
\hline 3 - car and hired mc & 0.66 & 0.60 & 0.61 & 0.62 & 0.63 & 0.63 & 0.64 \\
\hline 4 - car and taxi & 0.25 & 0.24 & 0.24 & 0.24 & 0.24 & 0.25 & 0.25 \\
\hline 5 - mc chain & 16.42 & 15.90 & 16.00 & 16.11 & 16.22 & 16.33 & 16.43 \\
\hline $6-\mathrm{mc}$ and bus & 13.38 & 14.04 & 13.91 & 13.78 & 13.65 & 13.52 & 13.40 \\
\hline $7-m c$ and hired $m c$ & 2.91 & 2.76 & 2.79 & 2.82 & 2.85 & 2.88 & 2.91 \\
\hline $8-m c$ and taxi & 0.25 & 0.24 & 0.24 & 0.24 & 0.24 & 0.24 & 0.25 \\
\hline 9 - bus & 37.26 & 38.33 & 38.25 & 38.17 & 38.09 & 38.01 & 37.94 \\
\hline $10-$ hired $m c$ & 3.16 & 3.03 & 3.07 & 3.10 & 3.14 & 3.17 & 3.21 \\
\hline $11-\operatorname{taxi}$ & 0.58 & 0.56 & 0.57 & 0.57 & 0.58 & 0.58 & 0.59 \\
\hline
\end{tabular}

traffic congestion since there is very high tendency over comfort, convenience, safety and privacy of vehicle use. Furthermore, the travel time saving relating to vehicle use is always benefited for travelers as they can devote that time to work and earn.

Therefore, the policies should be effectively influenced to change the prevailing attitudes of travelers. The proposed policy analysis is mainly incorporated with "push and pull" concept where vehicle taxation policy is implemented for the vehicles that enter to $C B D$ area while reducing public transport fares. The vehicle taxation is important in the sense of decreasing the rate of growth of vehicle usage as well. Several cases are studied by taking tax of $40 \mathrm{Baht} /$ vehicle with reducing public transport fares in steps of $10 \%$ from actual fares. Table 2 shows the modal share variation relating with different situations.

\section{(2) Results and discussion}

According to the results, it is clearly noticed that there is a considerable reduction of car travel with 40 Baht vehicle tax and simultaneous reductions of transit fares. Therefore, the variations of modal shares are corresponding with the theoretical expectations.

By contrast, when 40 Baht tax and $50 \%$ fare reduction is implemented, the related modal shares for car travel (alternative 1 4) is reduced by $4 \%$. Similarly, modal shares for bus travel, alternatives 6 and 9 , increase by $3.5 \%$.

Considering the hyper-congestion levelin the city of Bangkok, the expectation of restraining car travel is higher than that is obtained in this study. Therefore, policies are to be decided with wider perspective such as area-licensing systems or cordon taxing schemes together with implementing different tax rates in different periods of a day considering the congestion peak periods. Thereby, it will reduce car travel during congestion peak periods, and it will also encourage people to travel during less congested periods. The developed NL model will be investigated for a detail policy based analysis as a future study.

\section{CONCLUSIONS}

This study develops a methodology to investigate household travel behavior concerning two-traveler households for implementation of congestion reduction strategy in developing countries. The NL model is found to be a suitable technique to visualize the dynamic aspects of household mobility.

The developed NL model meaningfully demonstrates the behavioral realism relating to the trip chaining, especially for vehicle using households. The most important factors, which encourage trip chaining, are identified as proximity of the destination zones and time compatibility concerning both travelers into consideration. When the households' travel touches or passes CBD zones, the negative impact on car chaining alternative is observed, which explains the difficulty of making car chains in highly congested areas.

This analysis also reveals that male commuters highly contribute to create trip chains in developing 
countries, enhancing the findings of Mauch and Tailor ${ }^{7)}$.

The developed model significantly fits with the data, and the findings of this research can be meaningfully interpreted for the household travel behavior in developing countries. Furthermore, the policy analysis of vehicle taxation in addition to transit fare reductions supports to restrain the congestion problems into some extent.

\section{REFERENCES}

1) Wegmann. F. J. and Jang, T. Y.: Trip linkage patterns for workers. Journal of Transportation Engineering, ASCE, Vol. 124, pp. 264-270, 1998.

2) Jou, R. C. and Mahmassani, H. S.: Comparative analysis of day-to-day trip-chaining behavior of urban commuters in two cities, Transportation Research Record 1607, pp. 163170, 1997.

3) Ben-Akiva, M. and Bowman, J. L.: Activity scheduling and the analysis of activity patterns. EIRASS Conference on Activity-based Approaches, Eindhoven University of Technology, The Netherlands, 1995.

4) Adler, T. and Ben-Akiva, M.: A theoretical and empirical model of trip chaining behavior, Transportation Research $B$, Vol. 13, pp. 243-257, 1979.

5) Kitamura, R.: Incorporating trip chaining into analysis of destination choice, Transportation Research B, Vol. 18(1), pp. 67-81, 1984.

6) Goulias, K. G. and Kitamura, R.: Recursive model system for trip generation and trip chaining. Transportation Research Record 1236, pp. 59-66. 1989.

7) Mauch, M. and Taylor, B. D.: Gender, race, and travel behaviour: Analysis of household-serving travel and commuting in San Francisco bay area, Transportation Research Record 1607, pp. 147-153, 1997.

8) Strathman, J. G.. Dueker, K. J. and Davis, J. S.: Effects of household structure and selected travel characteristics on trip chaining, Transportation. Vol. 21, pp. 23-45. 1994.

9) Sobel, K. L.: Travel demand forecasting by using the nested multinomial logit model. Transportation Research Record 775, pp. 48-55, 1980.

10) Ortuzar, J. de D.: Nested logit models for mixed-mode travel in urban corridors, Transportation Research $A$, Vol. 17(4). pp. 283-299, 1983.
11) Talvitie, A: Planing model for transportation corridors, Transportation Research Record 673, pp. 106-112, 1978.

12) Mannering, F., Murakami, E. and Kim, S. G.: Temporal stability of travelers' activity choice and home-stay duration: Some empirical evidence, Transportation, 21, pp. 371-392, 1994.

13) Recker, W. W.: The household activity pattern problem: general formulation and solution, Transportation Research $B$, Vol. 29(1), pp. 61-77, 1995.

14) Wee, B. V.: The treatment of traffic in the Dutch environmental outlooks: The role of science in policy making and policy evaluation, Transportation Planning and Technology, Vol. 19, pp. 265-274, 1996.

15) Acutt, M. Z.: Modeling greenhouse gas emissions from cars in Great Britain, Transportation Planning and Technology, Vol. 19, pp. 191-206, 1996.

16) Himanen, V.: Possible transport policies for urban areas during the 1990's, Transportation Planning and Technology, Vol. 17, pp. 331-339, 1993.

17) Scott, D. M., Kanaroglou, P. S. and Anderson, W. P.: Impacts of commuting efficiency on congestion and emissions: Case of the Hamilton CMA, Canada, Transportation Research D, Vol. 2(4), pp. 245-257, 1997.

18) Salomon, I. and Mokhtarian, P. L.,: Coping with congestion: Understanding the gap between policy assumptions and behavior, Transportation Research D, Vol. 2(2), pp. 107-123, 1997.

19) Urban Transport Database and Model Development Project (UTDM), Office of the Commission for the Management of Land Traffic (OCMLT), Final Report Vol. $1 \& 2$, March 1998.

20) Environmental Atlas: Bangkok Metropolitan Area, Final Report of the Study on Urban Environmental Improvement Program in Bangkok Metropolitan Area (BEIP Study), Pacific Consultants International, and Suuri-Keikaku Co., Ltd., Feb 1997.

21) Ben-Akiva, M. and Lerman, S.: Discrete Choice Analysis, MIT Press, Cambridge, Massachusetts, 1985.

22) Forinash, C. V. and Koppelman, F. S. Application and interpretation of nested logit models of intercity mode choice, Transportation Research Record 1413, pp. 98-106, 1993.

(Received October 12, 2000)

\title{
世帯内複数旅行者を考慮した
}

発展途上国におけるトリップチェインー交通手段選択モデル

\author{
Dilum DISSANAYAKE・森川高行
}

発展途上国では，自家用車や二輪車の保有率はかなり増加しているものの，複数の自家用車・二輪車を 保有している世帯はごく限られているため, 送迎を中心とした過大なトリップチェインが形成され, 道路 混雑を一層深刻なものとしている. そこで本研究では，世帯内の複数旅行者によるトリップチェインの形 成と交通手段選択行動をネスティッドロジットモデルの枠組みでモデル化し，バンコクで収集したデータ に適用した。構築されたモデルを用いて，都市圈における自動車利用に対する「アメとムチ」型の交通政 策を行った場合の交通量削減効果の分析も行った。 